phate and reserpine, and one a preparation of sulphamethizole and sulphamethoxypyridazine. Two of these drugs have in earlier reports been described as inducing CAH.":3 The remaining three patients had been treated with nitrofurantoin as the only drug before jaundice appeared (two for two years and one for two months)

The liver damage of these last three patients was demonstrated by raised serum bilirubin, transaminase (aspartate aminotransferase and alanine aminotransferase) and alkaline phosphatase levels. The serum albumin concentration was low, the gammaglobulin fraction serum electrophoresis was greatly increased, and the half life of intravenous galactose was considerably prolonged. All three patients had antinuclear factor in titres of $1 / 100-1 / 500$ and smooth muscle antibodies in titres of 1 10-125. Liver bionsy specimens showed infiltrations of lymphocytes and plasma cells as well as scattered areas of necrosis-a picture consistent with CAH in an early phase. After withdrawal of nitrofurantoin clinical and laboratory recovery occurred in two patients without the use of immunosuppressive treatment.

During follow-un (1-6 years) the abovementioned laboratory values returned to normal in all patients with the single exception of a slightly prolonged half life of intravenously administered galactose in one patient six years after the acute illness. Liver biopsy specimens were obtained from two patients and were considered normal.

On the basis of the present findings we conclude that nitrofurantoin should be added to the number of drugs known as possible inducers of $\mathrm{CAH}$.

A STRÖMBERG B WENGLE

Department of Infectious Diseases and

Department of Internal Medicine,

University Hospital,

Uppsala,

Klemola, H, et al, Scandinavian fournal of Gustroenterology, 1975, 10,501.
Reynolds, T B, Yamada, S, and Peters, R L, Clinical Tonder, M, Nordoy, A,

Tönder, M, Nordöy, A, and Elgjo, K, Scandinavian
fournal of Gastroenterolgy, 1974,9,93.

\section{Serum digoxin in patients with thyroid} disease

SIR,-We read with interest the article by Drs $M$ S Croxson and $\mathrm{H}$ K Ibbertson 6 September $1975, \mathrm{p} 566$ ) in which they reported finding higher levels of serum digoxin in patients with hypothyroidism and lower levels in those with hyperthyroidism after oral digoxin administration. According to the authors' explanation the lower serum digoxin level in hyperthyroid patients is a consequence of elevated glomerular filtration rate and vice versa.

We should like to offer a possible alternative explanation of the data reported. Some drugs, like barbiturates or oral contraceptives, stimulate the activity of the enzymes in the endoplasmic reticulum of the liver, an effect known as enzyme induction. It has been shown that an increase in D-glucaric acid excretion is a result of the induction of the glucuronic acid pathway; hence an increase in urinary Dglucaric acid excretion is regarded as an indicator of enzyme induction. ${ }^{2}$

We examined the D-glucaric acid excretion of 21 thyrotoxic patients by the method of Marsh. ${ }^{3}$ The patients were receiving no medication. As is shown in the accompanying

\begin{tabular}{l|c|c}
\hline \multicolumn{1}{c|}{ Group } & $\begin{array}{c}\text { No of } \\
\text { cases }\end{array}$ & $\begin{array}{c}\text { D-glucaric acid } \\
\text { excretion in } \mu \text { mol } 24 \mathrm{~h} \\
\text { (mean : SE of mean) }\end{array}$ \\
\hline $\begin{array}{l}\text { Controls } \\
\text { Hyperthyroid } \\
\text { patients } \\
\begin{array}{c}\text { Patients under } \\
\text { antiepileptic } \\
\text { medication }\end{array}\end{array}$ & 216 & $123 \cdot 3: 65 \cdot 4\} \mathrm{P}<0.005$ \\
\hline
\end{tabular}

Concersion: SI to traditional units-D-Glucaric acid $1: \mathrm{mol}=0.2 \mathrm{mg}$.

table, D-glucaric acid excretion was increased in most hyperthyroid patients as compared with control subjects. From this we conclude that in thyrotoxicosis also the enzymes of the glucuronic acid sequence are stimulated.

Smith and Haber have reviewed the knowledge about digoxin pharmacokinetics. According to their views the metabolism of digoxin and its excretion in the form of metabolites appears to be quantitatively insignificant in relation to its elimination in unchanged form. Our finding, however, points to the importance of hepatic transformation processes which can be enhanced by thyroid hormones as "endogenous enzyme inducers."

We suggest that in addition to the elevated glomerular filtration rate this phenomenon may act towards an increase of digoxin elimination in hyperthyroid patients.

A VÁRAD

J FÖLDES

First Department of Medicine,

Semmelweis University Medical School, Budapest, Hungary

Mowat, A P, fournal of Endocrinology, 1968, 42, 585. Hunter, J, et al, Lancet, 1971, 1, 572 .

Marsh, C A, Biochemical fournal, 1963, 86, 77. Smith, T W and Haber, E, New England fournal of
Medicine, 1973, 289, 1063 .

\section{Exposure to asbestos dust}

SIR,-In your recent leading article (5 June, p 1361) on this subject the relationship between diffuse mesothelioma of the pleura and asbestos inhalation was discussed. There was no mention of the relationship between asbestos inhalation or ingestion and mesothelioma of the peritoneum, although this relationship has been recorded on several occasions in the past. ${ }^{1}$ :

A 41-year-old man who had worked for a thermal insulation firm for over 20 years recently presented at this hospital with abdominal swelling, anorexia, and weight loss. He had been investigated two years previously for asbestosis, but at that time there was no specific evidence of any involvement of his lungs in this condition. Examination on this admission revealed that he was cachectic, with a palpable abdominal mass and ascites. A presumptive diagnosis of carcinomatosis peritonei was made and he was subjected to laparotomy. The omentum was heavily infiltrated with a nodular, firm, white tumour which was cystic in consistency. In addition, there was a separate while plaque of tumour in the left paracolic gutter. No lesion was palpable in the gastrointestinal tract and the liver was not obviously involved with secondary deposits. The great omentum was excised and a biopsy specimen taken from the plaque in the left paracolic gutter. The histological appearance of both specimens was consistent with a diagnosis of primary malignant mesothelioma of the peritoneum

This case demonstrates the typical clinical findings in a patient presenting with a primary mesothelioma of the peritoneum. The pathogenesis of the condition is open to speculation, but it is probably due to the spread of a carcinogen from pleura to peritoneum across the transphrenic lymphatics after exposure to asbestos dust." The possibility of this diagnosis should always be borne in mind in young people presenting with malignant ascites in whom exposure to asbestos can be elicited.

D C BRITTON

Royal Victoria Infirmary Newcastle upon Tyne

' Enticknap, J B, and Smither, W J, British fournal of Industrial Medicine, 1964, 21, 20. Mann, R H, Grosh, J L, and O'Donnell, W M, Cancer,
1966, 19, 521 .

\section{Ultrasonic monitoring of fetal respiratory movement}

SIR,-I read with interest the article by $\mathrm{Mr} \mathrm{R} N$ Tremewan and others (12 June, $p$ 1434) but find the complete absence of evidence about the clinical application of the method described somewhat surprising. One gets the impression that only two fetuses have been examined.

The idea of recording both proximal and distal fetal chest wall echoes is by no means new, but all those who have tried it to date have found that it is virtually impossible to maintain stable echoes from these two structures for any significant length of time in even a small proportion of patients. The authors suggest that this technique facilitates the recognition of artefact due to translational movement of the fetus but produce no evidence of this. I can assure them that translational movements of the fetus will invariably result in the loss of the two echoes they are trying to monitor.

It seems strange that they should say that it is helpful to record fetal chest wall velocity and then include a statement that the use of the time-position display on the Diasonograph provides definitive information on the nature of the chest wall movement.

In clinical use the fetal breathing monitoring system must produce continuous records for an absolute minimum of 10 minutes in order to provide clinically valuable information and should be capable of detecting movements of less than $0.5 \mathrm{~mm}$ in order to detect reliably the majority of chest wall excursions. ${ }^{1}$ There is no evidence that the system described in this paper would satisfy either of these criteria.

Hylton B Meire

Division of Radiology,

Clinical Research Centre,

Harrow, Middx

Meire, H B, et al, British fournal of Radiology, 1975

* We sent a copy of this letter to Mr Tremewan and his colleagues, whose reply is printed below.-ED, $B M \mathcal{H}$.

SIR,-In reply to Dr Meire's letter we wish to make the following comments.

The purpose of our paper was to describe a system which enables fetal respiratory movement to be identified and studied without ambiguity resulting from confusion with other fetal or maternal movements. The evidence for this is clearly depicted in figs 1 and 3 of our paper, which demonstrate respiratory movements from proximal and distal fetal chest walls simultaneously.

Translational fetal movements do not invariably result in loss of the two signals, but if this occurs both signals can usually be 